\title{
Genetic polymorphisms of Plasmodium falciparum isolates from Melka-Werer, North East Ethiopia based on the merozoite surface protein-2 ( $m s p-2)$ gene as a molecular marker
}

\author{
Hussein Mohammed ${ }^{1 *}$ (D), Ashenafi Assefa ${ }^{1}$, Melkie Chernet ${ }^{1}$, Yonas Wuletaw ${ }^{1}$ and Robert J. Commons ${ }^{2,3}$
}

\begin{abstract}
Background: The characterization of parasite populations circulating in malaria endemic areas is necessary to evaluate the success of ongoing interventions and malaria control strategies. This study was designed to investigate the genetic diversity of Plasmodium falciparum isolates from the semi-arid area in North East Ethiopia, using the highly polymorphic merozoite surface protein-2 (msp2) gene as a molecular marker.

Methods: Dried blood spot isolates were collected from patients with P. falciparum infection between September 2014 and January 2015 from Melka-Werer, North East Ethiopia. Parasite DNA was extracted and genotyped using allele-specific nested polymerase chain reactions for msp2.

Results: 52 isolates were collected with msp2 identified in 41 (78.8\%) isolates. Allele typing of the msp2 gene detected the 3D7/IC allelic family in 54\% and FC27 allelic family in 46\%. A total of 14 different msp2 genotypes were detected including 6 belonging to the 3D7/IC family and 8 to the FC27 family. Forty percent of isolates had multiple genotypes and the overall mean multiplicity of infections (MOI) was $1.2(95 \% \mathrm{Cl} 0.96-1.42)$. The heterozygosity index was 0.50 for the msp2 locus. There was no difference in $\mathrm{MOI}$ between age groups. A negative correlation between parasite density and multiplicity of infection was found ( $p=0.02)$.

Conclusion: Plasmodium falciparum isolates from the semi-arid area of North East Ethiopia are mainly monoclonal with low $\mathrm{MOl}$ and limited genetic diversity in the study population.
\end{abstract}

Keywords: Ethiopia, Genotyping, Polymorphism, Merozoite surface protein 2, Multiplicity of infection

\section{Background}

In the past decade, malaria morbidity and mortality have decreased significantly worldwide. In 2018, an estimated 228 million cases of malaria occurred worldwide, compared with 251 million cases in 2010 [1]. Ethiopia is one of the African countries where Plasmodium falciparum

\footnotetext{
*Correspondence: hussein_ehnri@yahoo.com

${ }^{1}$ Malaria, Neglected Tropical Diseases Research Team, Bacterial, Parasitic, Zoonotic Diseases Research Directorate, Ethiopian Public Health Institute, Addis Ababa, Ethiopia

Full list of author information is available at the end of the article
}

and Plasmodium vivax co-exist; with P. falciparum accounting for almost $70 \%$ of cases [2].

In Ethiopia, malaria remains a major public health problem with an estimated $52 \%$ of the population at risk of infection $[2,3]$. However, due to improved case management, and the scale-up of long-lasting insecticidal nets (LLINs) and indoor residual spraying (IRS) there has been a significant reduction in the malaria burden, with the malaria programme review in 2020 finding a $67 \%$ decline in malaria prevalence from $0.9 / 100,000$ population to $0.3 / 100,000$ population between 2016 and 2020 [4]. The estimated annual parasite index in the

(c) The Author(s) 2021. This article is licensed under a Creative Commons Attribution 4.0 International License, which permits use, sharing, adaptation, distribution and reproduction in any medium or format, as long as you give appropriate credit to the original author(s) and the source, provide a link to the Creative Commons licence, and indicate if changes were made. The images or other third party material in this article are included in the article's Creative Commons licence, unless indicated otherwise in a credit line to the material. If material is not included in the article's Creative Commons licence and your intended use is not permitted by statutory regulation or exceeds the permitted use, you will need to obtain permission directly from the copyright holder. To view a copy of this licence, visit http://creativeco mmons.org/licenses/by/4.0/. The Creative Commons Public Domain Dedication waiver (http://creativecommons.org/publicdomain/ zero/1.0/) applies to the data made available in this article, unless otherwise stated in a credit line to the data. 
Afar region in North East Ethiopia was 52.03 in 2019 compared to 126 in 2013 (Federal Ministry of Health, unpublished data). In most malaria endemic districts, the annual malaria incidence rate is now less than $5 \%$ [5, 6]. These successes have prompted the country to move towards malaria elimination strategies [7].

Polymerase chain reaction (PCR)-based genotyping methods are used widely in molecular epidemiological studies to assess allelic diversity and multiplicity of infection [8]. Among the polymorphic genes of $P$. falciparum, merozoite surface protein 1 ( $m s p 1)$, $m s p 2$, and glurp markers are used most commonly to differentiate recrudescence of the parasite from new infections in therapeutic efficacy studies [8]. The $m s p 2$ gene is the most conserved and informative single marker for molecular epidemiological studies [9]. MSP2 is a glycoprotein expressed on the surface of merozoites that has been considered as one of the candidates for blood stage malaria vaccines [10]. The $m s p 2$ gene is located on chromosome 2 and is composed of five blocks the most polymorphic of which is the central block 3 [11]. The gene is encoded by highly divergent alleles, grouped into two dimorphic families FC27 and IC/3D7 [12]. Genotyping of P. falciparum in malaria endemic areas can be used to determine the genetic diversity of falciparum malaria and multiplicity of infection (MOI), which can be used to infer transmission intensity. For example, studies higher heterozygosity $(\mathrm{He})$ and MOIs have been described in high malaria transmission areas compared with low transmission areas $[13,14]$.

Several studies have investigated the genetic diversity of $P$. falciparum in endemic regions in Africa, South America and Asia [15-17], including a few studies from Ethiopia [18-21]. Most of these studies were conducted in moderate to high trasmision settings and showed high genetic diversity and MOI. However, no studies have described the diversity of $P$. falciparum from the semi-arid climatic zones of Ethiopia. Given the recently enhanced malaria control interventions in Ethiopia, assessment of the genetic diversity of $P$. falciparum provides an additional understanding of progress towards elimination in the country and a point of comparison for future studies in the region. This study aimed to determine the genetic diversity and multiplicity of $P$. falciparum infection based on $m s p 2$ gene polymorphisms in the semi-arid rural area of North East Ethiopia.

\section{Methods}

\section{Study site}

The study samples were collected from Melka-Werer rural area in Afar Regional state in North East Ethiopia, a sentinel site for monitoring of anti-malarial therapeutic efficacy (Fig. 1). The study area is located $291 \mathrm{~km}$ northeast of Addis Ababa at an altitude of $723 \mathrm{~m}$ above sea level. Melka-Werer is one of the kebeles of Amibara district, with a catchment population 61,222 inhabitants; the majority living as pastoralists or semi-pastoralists [22]. The semi-arid climatic zone has a long hot summer, and a short mild winter with annual rainfall between 200 and $500 \mathrm{~mm}$. Malaria transmission is markedly seasonal, with a peak during August to December. Plasmodium falciparum and $P$. vivax are the two dominant malaria parasites in the region. The local vector responsible for most malaria transmission is Anopheles arabiensis with mosquito breeding predominantly occurring adjacent to the Awash River and malaria distribution reflecting this. The prevalence of malaria in this region is declining according to Ethiopian national malaria indicator surveys; with a cross-sectional prevalence of $2.4 \%$ in $2007,0.8 \%$ in 2011 and $0.2 \%$ in $2015[6,23,24]$.

\section{Study population and sample collection}

Dried blood spot samples were collected from children and adults presenting to the Melka-Werer Health Centre with $P$. falciparum malaria and enrolled into a 28-day therapeutic efficacy of artemether-lumefantrine which found $100 \%$ adequate clinical and parasitological responses. The study was conducted from September 2014 to January 2015. Individuals with an axillary temperature of $\geq 37.5{ }^{\circ} \mathrm{C}$ or history of fever within the previous $24 \mathrm{~h}$, haemoglobin $(\mathrm{Hb})$ level $>5 \mathrm{~g} / \mathrm{dL}$, microscopically confirmed $P$. falciparum mono-infection with asexual parasite densities between 1,000 and 100,000 parasites $/ \mu \mathrm{L}$ blood and residence within the study area were eligible for enrolment in the study [25]. Thick and thin blood films were stained with 3\% Giemsa for 45 min and slides were read by two health centre laboratory technicians. In case of discordant results, a third WHOcertified microscopist resolved the discrepancy. Using the thick blood film, asexual parasitaemia was counted against 200 leucocytes and expressed as the number of asexual parasites $/ \mu \mathrm{L}$ of blood, assuming a leucocyte count of $8,000 / \mu \mathrm{L}$ of blood [26]. Haemoglobin was measured from finger prick blood samples using a portable spectrophotometer (HemoCue Ängelholm Sweden). Before treatment, approximately $50 \mu \mathrm{L}$ of blood from each patient was spotted onto Whatman $903^{\circledR}$ filter paper (Schleicher \& Schuell BioScience), air-dried and stored in labelled zip lock bags with desiccant before being transported and stored at $-20{ }^{\circ} \mathrm{C}$ from 2015 to 2020 in the Malaria Research Laboratory at the Ethiopian Public Health Institute (Fig. 2).

\section{Parasite DNA extraction and molecular genotyping}

DNA was extracted from the dried blood spots using the Chelex-Saponin method [27] and allelic familyspecific analyses of $m s p 2$ block 3 were carried out as 


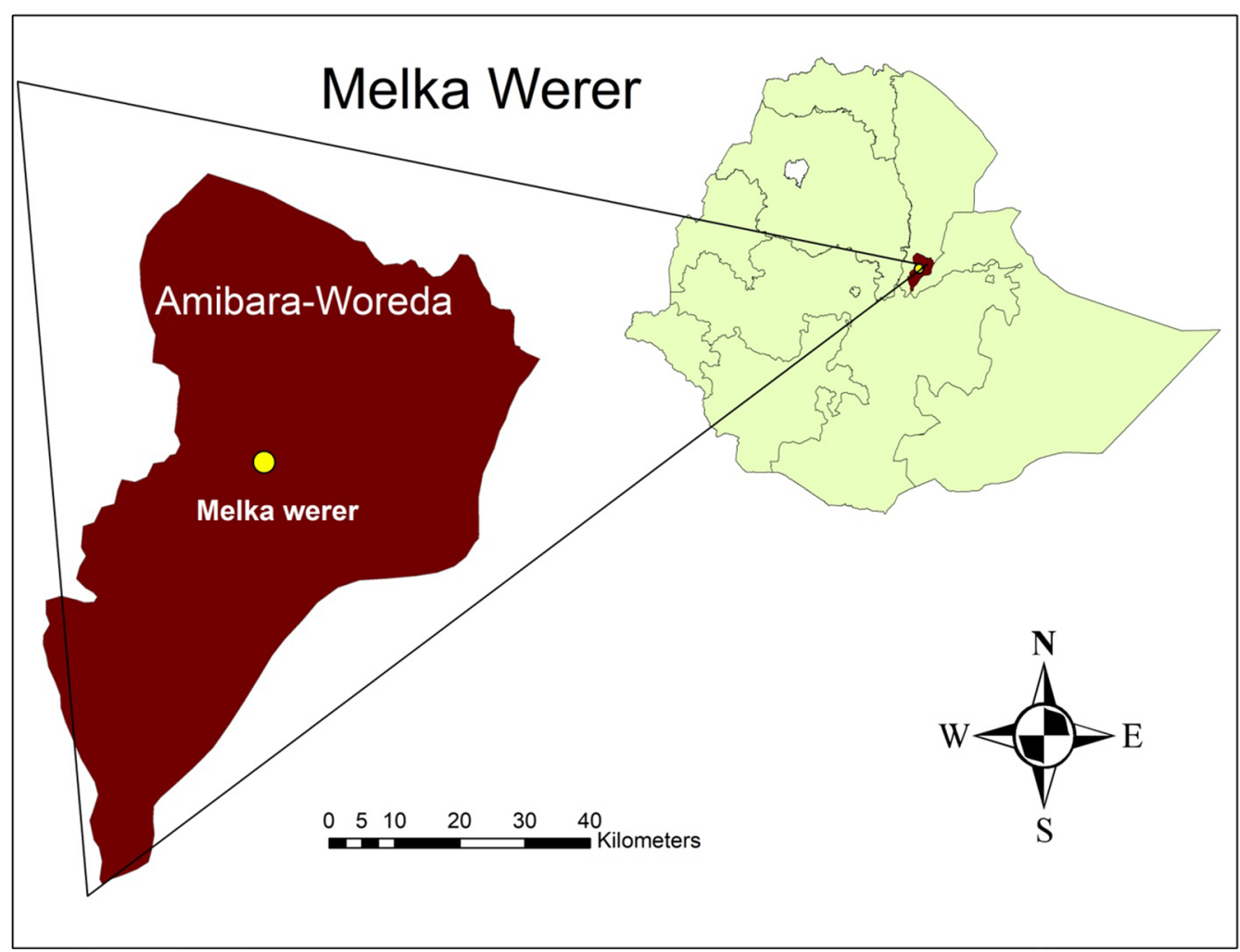

Fig. 1 Map of the sample collection area, Meleka-Werere, North East, Ethiopia

previously described [20]. The allele- specific positive control 3D7 and DNA free negative controls were included in each set of reactions [16]. The nested PCR products were separated by electrophoresis on $2 \%$ agarose gel in $1 \mathrm{X}$ TBE (Tris borate EDTA) buffer stained with $0.5 \%(\mathrm{v} / \mathrm{v})$ ethidium bromide at $80 \mathrm{~V}$ for $30 \mathrm{~min}$. After running the gel, it was placed in a gel documentation system (Cleaver Scientific UV Transilluminator, UK) that was connected to a desktop computer to visualize the bands under ultraviolet transillumination. The size of DNA fragments was estimated visually based on their mobility related to a 100 bp DNA ladder marker (Boehringer Mannheim Marker VI). Alleles in each family were considered the same if fragment size was within a $20 \mathrm{bp}$ interval [28]. The MOI was calculated by dividing the total number of distinct $m s p 2$ fragments observed by the number of positive samples. Isolates with a single genotype were considered monoclonal infections and those with more than one genotype as polyclonal infections. The frequency of monoclonal infections was the number of patients with one parasite genotype divided by the total infected population. Heterozygosity index was calculated using the following formula $\mathrm{He}=\mathrm{n} /(\mathrm{n}-1)\left(1-\Sigma \mathrm{Pi}^{2}\right)$, where $\mathrm{n}$ is the number of isolates sampled and Pi is the allele frequency [29].

\section{Statistical analysis}

Data were recorded in Excel and analysed with SPSS version 20 (SPSS Inc., Chicago, IL, USA). The frequency of $m s p 2$ allelic families was calculated as a proportion of all detected alleles in the isolates. Spearman's rank correlation coefficient was calculated to assess the association between MOI and mean parasite density and age. The non-parametric Mann-Whitney U test was used to compare the association between MOI and previous exposure to malaria. A $P$ value $<0.05$ was considered statistically significant.

\section{Results}

\section{Study population}

A total of 72 patients were confirmed to have malaria. Of these, $52(72 \%)$ patients were confirmed to have P. falciparum malaria and were genotyped for the msp2 alleles. An equal proportion of males (26, 50\%) and females $(26,50 \%)$ were enrolled. The patients' ages ranged from two to 60 years (mean $21.3 \pm 14.4$ ). The geometric mean parasitaemia was 3,661 (95\% CI $2,768-4,877$ ) ranging from 1,000 to 83,200 parasites $/ \mu \mathrm{L}$ (Table 1). The mean axillary temperature was $38.1{ }^{\circ} \mathrm{C}$ (95\% CI $37.8-38.4) .90 .4 \%$ of the study participants 


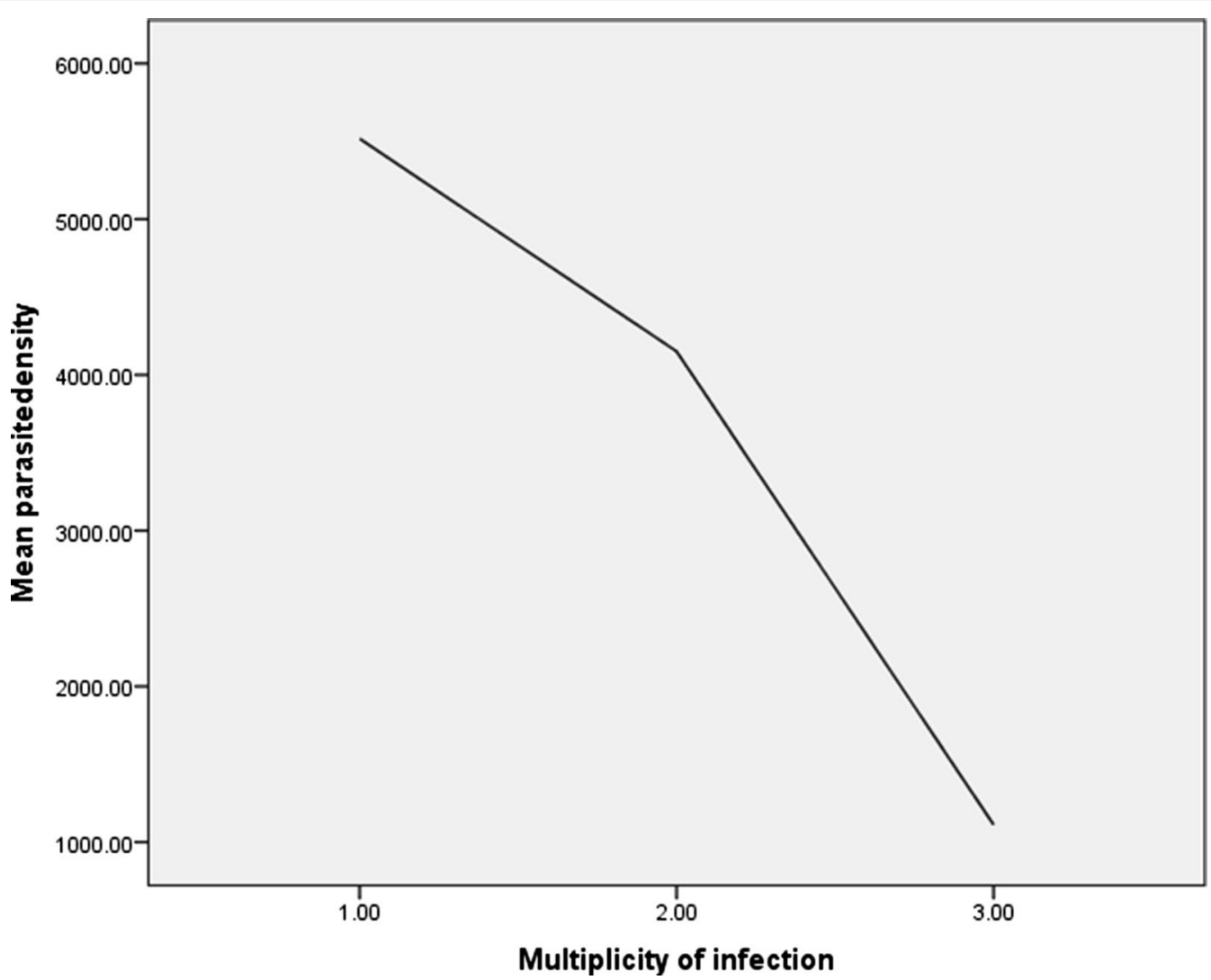

Fig. 2 Relationship between mean parasite density and multiplicity of infection of Plasmodium falciparum infection

Table 1 Demographic and parasitological characteristics of the study population from Melka-Werer, North East Ethiopia

\begin{tabular}{ll}
\hline Characteristic & Values \\
\hline Sex ratio (Male/Female) & $1(26 / 26)$ \\
Mean age \pm SD (years) & $21.3 \pm 14.4$ \\
Age range (years) & $2-60$ \\
Age group & \\
Children $(<10$ years) & $13(25.0 \%)$ \\
Children (10-20 years) & $14(26.9 \%)$ \\
Adults (> 20 years) & $22(48.1 \%)$ \\
Geometric mean parasitemia $(95 \% \mathrm{Cl})(\mathrm{p} / \mu \mathrm{L})$ & $3660.8(2768.3-4877.2)$ \\
Parasite density range $(\mathrm{p} / \mu \mathrm{L})$ & $1000-83,200$ \\
Mean axillary temperature $(95 \% \mathrm{Cl})\left({ }^{\circ} \mathrm{C}\right)$ & $38.1(37.8-38.4)$ \\
Mean haemoglobin $\pm \mathrm{SD}(\mathrm{g} / \mathrm{dL})$ & $11.9 \pm 1.8$
\end{tabular}

$S D$ standard deviation, $p / \mu /$ parasite per microliter

could not recall previous exposure to malaria. The geometric mean parasite density of individuals with previous exposure to malaria attack was higher 10,854 parasites/ $\mu \mathrm{L}$ compared with 3,226 parasites $/ \mu \mathrm{L}$ in those without prior exposure.

\section{Allele frequencies}

All samples positive for $P$. falciparum were genotyped for $m s p 2$ Block-3 by nested PCR. $m s p 2$ was identified in $41(78.8 \%)$ samples. A total of fourteen different alleles were identified in $m s p 2$ genotyping. Six alleles of 3D7/ IC (280-500 bp) and 8 alleles of FC27 (180-450 bp) were detected. The distribution of the corresponding band size is presented in Additional file 1: Figure S1. The proportion of isolates with only 3D7/IC and FC27 alleles was $34.1 \%(14 / 41)$ and $22.0 \%$ (9/41), respectively. Both $m s p 2$ allelic families were identified in $43.9 \%(18 / 41)$ of the isolates (Table 2). $40.4 \%(21 / 52)$ of the isolates contained multiple $m s p 2$ alleles and the overall mean MOI was 1.2 (95\% CI 1.00-1.40). The heterozygosity index for the msp2 locus was 0.5 .

\section{Relationship between $\mathrm{MOI}$, parasite density and age}

A negative correlation was observed between parasite density and MOI (Spearman rank coefficient $=-0.33$ $P=0.022$ ). Age was not correlated with the MOI (Spearman rank coefficient $=0.080 ; P=0.51$ ). The highest MOI 
Table 2 Distribution of $m s p 2$ allelic families of $P$. falciparum isolates from Melka-Werer, North East Ethiopia

\begin{tabular}{|c|c|c|c|c|}
\hline Allelic family & n (\%) & Fragment size (bp) & No. of alleles & Mean MOI \\
\hline msp2 & $41(100)$ & & & $1.2(95 \%$ Cl 1.00-1.40) \\
\hline FC27 & $9(22)$ & $180-450 \mathrm{bp}$ & 8 & $1.04(95 \%$ Cl 0.96-1.11) \\
\hline $3 \mathrm{D} 7 / \mathrm{IC}$ & $14(34)$ & $280-500 \mathrm{bp}$ & 6 & $1.06(95 \%$ Cl 0.97-1.15) \\
\hline $\mathrm{FC} 27+3 \mathrm{D} 7 / \mathrm{IC}$ & $18(44)$ & & & \\
\hline Total & 41 & & 14 & \\
\hline
\end{tabular}

$b p$ base pair, $\mathrm{Cl}$ Confidence Interval, $n$ number of samples, $\mathrm{MOI}$ multiplicity of infection

Table 3 Mean parasitemia and multiplicity of infection of Plasmodium falciparum msp2 gene stratified by age group $(n=52)$

\begin{tabular}{llll}
\hline Age (years) & $\mathbf{n}(\%)$ & $\begin{array}{l}\text { Parasite density } \\
\text { (parasite/ } \boldsymbol{\mu L})\end{array}$ & Mean MOI \\
\hline$<10$ & $13(25.0)$ & 12,382 & 1.00 \\
$10-18$ & $14(26.9)$ & 4754 & 1.50 \\
$>18$ & $25(48.1)$ & 4986 & 1.12 \\
\hline
\end{tabular}

$n$ number of malaria cases, $\mathrm{MOI}$ multiplicity of infection

was in the 10-18-year-old age group as shown in Table 3. There was no association between the MOI of individuals with previous exposure to malaria attack compared to those without previous exposure $(\mathrm{p}=0.935)$.

\section{Discussion}

This study was conducted to assess the current $P$. falciparum genotypic structure in the semi-arid area in North East Ethiopia, using the highly polymorphic (block 3 ) region of the $m s p 2$ gene as a molecular marker. The $m s p 2$ marker is recommended for genotyping $P$. falciparum parasite populations compared with $m s p-1$ and glurp [30]. Plasmodium falciparum isolates from this region were mainly monoclonal with a low MOI and limited genetic diversity. These findings are important for ongoing evaluation of the effect of malaria control strategies, as Ethiopia moves towards malaria elimination.

The 3D7/IC allelic family of $m s p 2$ was more prevalent than the FC27 allelic family. This is in agreement with previous reports from Burkina Faso [31], South West Ethiopia [22] and Sudan [32]. However, this finding differs to results from North West Ethiopia [20], and Central Sudan [33], where FC27 was the more prevalent allelic family. These differences could relate to the semiarid geographic setting and low transmission intensity compared to the hot and humid climate in North West Ethiopia.

Limited genetic diversity of $P$. falciparum was observed in this study. Similar results have been reported in other areas with low P. falciparum transmission [34] and in regions with declining transmission related to malaria control efforts [35]. In contrast, a high level of genetic diversity was reported in high endemicity settings in Cameroon [15] and Burkina Faso [31].

The current study found that the P. falciparum parasite population in Melka-Werer exhibited a low heterozygosity $(\mathrm{He}=0.5)$, consistent with that reported in Mubuga, Rwanda $(\mathrm{He}=0.49)$ [36]. In areas with declining local transmission, it is expected that lower parasite diversity (heterozygosity) will be present [37]. Declining diversity and transmission have been associated with improved malaria control interventions [38, 39].

The overall mean MOI reported in this study was low $(\mathrm{MOI}=1.2)$. This is in agreement to previous studies where low malaria transmission settings are commonly associated with lower MOIs [40, 41], and is consistent with reports from semi-desert settings in neighbouring Sudan and Djibouti [32, 38]. The low MOI contrasted with a finding from a higher endemic setting in Humera, Ethiopia [19]. The low MOI observed in this study may reflect most positive samples being from adult patients, with previous reports finding a reduction in MOI in adults compared with children [43].

The majority of participants in the current study were older than 10 years, similar to results from an area with a lower intensity of malaria transmission [31] but contrasting to reports from high transmission settings [44]. It is also possible that the age-related malaria risk may have been influenced by implementation of effective malaria control interventions, such as the widespread distribution of long-lasting insecticidal nets (LLINs) and indoor residual spray (IRS), and sustained treatment of malaria patients with artemisinin-based combination therapy (ACT). This is supported by the 2015 malaria indicator survey, which found that the Afar region had the highest percentage of use of LLINs compared to other regions of the country [6].

Age is considered an important factor in the acquisition of immunity against $P$. falciparum and may have also an effect on MOI [45], although, the influence of age on the MOI is highly affected by malaria transmission intensity [46]. Previous studies have shown an association 
between age and MOI in areas with intense perennial malaria transmission or hypo-meso-endemic malaria transmission [47, 48]. However, the current study found no association between age and MOI. Similar findings have been reported in other countries $[49,50]$.

A higher geometric mean parasite density in individuals with previous exposure to malaria attack was found. In this low endemicity setting, a lower proportion of individuals will have likely had prior immunity, meaning that infected patients will be more likely to become symptomatic at a lower parasitaemia than in high endemicity settings.

It was difficult to correlate transmission levels with genetic diversity and MOI in the current study due to a lack of entomologic inoculation rate (EIR) data from the study area. However, the genetic diversity and the MOI reported in the present study supported a low average microscopy positivity rate $(8.5 \%)$ (Melka-Werer rural town health office data, 2015, unpublished). A limitation of this study was the small sample size, in part due to the nomadic nature of the local communities. Furthermore, due to resource restrictions, lower discriminatory power agarose gel electrophoresis compared to capillary electrophoresis was used [51]. Further, the limited allelic frequency and genetic diversity observed may have been due to the detection limit of the PCR technique used in the study. Allelic fragment length intervals of less than 20 base pairs may not be clearly distinguished on agarose gel and may lead to misclassification of the genotype. Allele differentiation could be improved by using more discriminatory techniques in future studies, such as DNA sequencing or SNPs.

\section{Conclusion}

This study found limited genetic diversity of $P$. falciparum isolates from the semi-arid area of North East Ethiopia, with most infections monoclonal. This correlates with the low prevalence of infection in this region. There is a need for further studies in similar low transmission settings with larger sample sizes using capillary electrophoresis to further investigate the dynamics of falciparum malaria diversity in such regions of Ethiopia.

\section{Supplementary Information}

The online version contains supplementary material available at https://doi. org/10.1186/s12936-021-03625-1.

Additional file 1: Fig. S1.

\section{Abbreviations}

bp: Base pair; msp2: Merozoite surface protein 2; MOI: Multiplicity of infection; PCR: Polymerase chain reaction.

\section{Acknowledgements}

The authors are grateful to the study participants and medical staff of the Melka Werer Health Center. The authors would like to acknowledge Haven sime for providing assistance for the statistical work and Mulugeta Guta for support in data collection.

\section{Authors' contributions}

HM was involved in all phases of the study including data collection, molecular analysis, data analysis, interpretation and write up. MC was involved in statistical analysis of data. AA and YW data collection and revised the manuscript. RJC contributed to write up and revised the manuscript. All authors read and approved the final manuscript.

\section{Funding}

Funding was partially obtained from Ethiopian Federal Ministry of Health $(\mathrm{FMoH})$. The funding agency did not play a role in the design of the study and collection of samples, analysis, interpretation of the data or writing of manuscript.

\section{Availability of data and materials}

The dataset supporting the conclusion of this article of this article is included within the article and the additional files.

\section{Ethics approval and consent to participate}

Ethics approval for the study was granted by the Institutional Review Board (IRB) of the Ethiopian Public Health Institute (EPHI). Written informed consent was obtained from parents or guardians prior to recruitment.

\section{Consent for publication}

Not applicable.

\section{Competing interests}

The authors declare that they have no competing interests.

\section{Author details}

${ }^{1}$ Malaria, Neglected Tropical Diseases Research Team, Bacterial, Parasitic, Zoonotic Diseases Research Directorate, Ethiopian Public Health Institute, Addis Ababa, Ethiopia. ${ }^{2}$ Global Health Division, Menzies School of Health Research, Charles Darwin University, Darwin, Australia. ${ }^{3}$ Internal Medicine Services, Ballarat Health Services, Ballarat, Australia.

Received: 21 November 2020 Accepted: 4 February 2021

Published online: 12 February 2021

References

1. WHO. World malaria report 2018. Geneva: World Health Organization, 2019.

2. Federal Ministry of Health. Ethiopia malaria elimination strategic plan: 2021-2025. Ethiopia: Addis Ababa; 2020.

3. President's Malaria Initiative Ethiopia. Malaria Operational Plan FY; 2015.

4. Federal Ministry of Health. Ethiopian malaria programme review report. Addis Ababa; 2020.

5. Abeku TA, Helinski ME, Kirby M, Kefyalew T, Awano T, Batisso E, et al. Monitoring changes in malaria epidemiology and effectiveness of interventions in Ethiopia and Uganda: beyond Garki project baseline survey. Malar J. 2015;14:337.

6. Institute EPH. Ethiopian malaria indicator survey. Ethiopia: Addis Ababa; 2015.

7. Federal Ministry of Health. National strategic plan for malaria prevention control and elimination in Ethiopia, 2011-2015. Ethiopia: Addis Ababa; 2010.

8. Bakhit AM, Abdel-Muhsin AM, Elzaki SE, Al-Hashami Z, Albarwani HS, Al-Qamashoui BA, et al. Plasmodium falciparum population structure in Sudan post artemisinin-based combination therapy. Acta Trop. 2015;148:97-104

9. Cattamanchi A, Kyabayinze D, Hubbard A, Rosenthal PJ, Dorsey G. Distinguishing recrudescence from reinfection in a longitudinal antimalarial drug efficacy study: comparison of results based on genotyping of msp 1, msp2, and glurp. Am J Trop Med Hyg. 2003;68:133-9. 
10. Mwingira F, Nkwengulila G, Schoepflin S, Sumari D, Beck HP, Snounou G, et al. Plasmodium falciparum msp 1, msp2 and glurp allele frequency and diversity in sub-Saharan Africa. Malar J. 2011;10:79.

11. Patel P, Bharti PK, Bansal D, Raman RK, Mohapatra PK, Sehgal R, et al. Genetic diversity and antibody responses against Plasmodium falciparum vaccine candidate genes from Chhattisgarh, Central India: implication for vaccine development. PLOS ONE. 2017:12:e0182674

12. Ferreira MU, Hartl DL. Plasmodium falciparum: worldwide sequence diversity and evolution of the malaria vaccine candidate merozoite surface protein-2 (MSP-2). Exp Parasitol. 2007;115:32-40.

13. Babiker HA, Lines J, Hill WG, Walliker D. Population structure of Plasmodium falciparum in villages with different malaria endemicity in East Africa. Am J Trop Med Hyg. 1997;56:141-7.

14. Mobegi VA, Loua KM, Ahouidi AD, Satoguina J, Nwanma DC, AmambuaNgwa A, et al. Population genetic structure of Plasmodium falciparum across a region of diverse endemicity in West Africa. Malar J. 2012;11:223.

15. Metoh TN, Chen JH, Gah PF, Zhou X, Somo RM. Genetic diversity of Plasmodium falciparum and genetic profile in children affected by uncomplicated malaria in Cameroon. Malar J. 2020;19:115.

16. Gosi P, Lanteri CA, Tyner SD, Se Y, Lon C, Spring M, et al. Evaluation of parasite subpopulations and genetic diversity of msp 1, msp2 and glurp genes during and following artesunate mono therapy treatment of Plasmodium falciparum malaria in Western Cambodia. Malar J. 2013;12:403.

17. Mohd Abd Razak, Sastu UR, Norahmad NA, Abdul-Karim A, Muhammad A, et al. Genetic diversity of Plasmodium falciparum populations in malaria declining areas of Sabah, East Malaysia. PLoS One. 2016;11:e0152415.

18. Abamecha A, El AH, Yilma D, Addisu W, Ibenthal A, Bayih AG, et al. Genetic diversity and genotype multiplicity of Plasmodium falciparum infection in patients with uncomplicated malaria in Chewaka district. Ethiopia Malar J. 2020;19:203.

19. Mohammed H, Kassa M, Mekete K, Assefa A, Taye G, Commons RJ. Genetic diversity of msp 1, msp2 and glurp of Plasmodium falciparum isolates in Northwest Ethiopia. Malar J. 2018;17:386.

20. Mohammed H, Kassa M, Assefa A, Tadesse M, Kebede A. Genetic polymorphism of Merozoite Surface Protein-2 (MSP-2) in Plasmodium falciparum isolates from Pawe District. North West Ethiopia PLoS One. 2017;12:e0177559.

21. Mohammed H, Mindaye T, Belayneh M, Kassa M, Assefa A, Tadesse M, et al. Genetic diversity of Plasmodium falciparum isolates based on $\mathrm{msp}-1$ and msp-2 genes from Kolla-Shele area, Arbaminch Zuria District, southwest Ethiopia. Malar J. 2015:14:73.

22. Legesse M, Ameni G, Mamo G, Medhin G, Shawel D, Bjune G, et al. Knowledge and perception of pulmonary tuberculosis in pastoral communities in the middle and Lower Awash Valley of Afar region. Ethiopia BMC Public Health. 2010;10:187.

23. Federal Ministry of Health Ethiopia. Ethiopian malaria indicator survey. Addis Ababa Ethiopia; 2007.

24. Ethiopian Public Health Institute. Ethiopian malaria indicator survey. Addis Ababa Ethiopia; 2011.

25. WHO. Methods for surveillance of anti-malarial drug efficacy. Geneva, World Health Organization, 2009

26. WHO. Basic malaria microscopy. Part I. Learner's guide. 2nd Edn. Geneva, World Health Organization, 2010.

27. Plowe CV, Djimde A, Bouare M, Doumbo O, Wellems TE. Pyrimethamine and proguanil resistance-conferring mutations in Plasmodium falciparum dihydrofolate reductase: polymerase chain reaction methods for surveillance in Africa. Am J Trop Med Hyg. 1995;52:565-8.

28. Mayengue PL, Ndounga M, Malonga FV, Bitemo M, Ntoumi F. Genetic polymorphism of merozoite surface protein-1 and merozoite surface polymorphism in Plasmodium falciparum isolates from Brazzaville. Republic of Congo Malar J. 2011;10:276.

29. Nei M. Estimation of average heterozygosity and genetic distance from a small number of individuals. Genetics. 1978:89:583-90.

30. Kidima W, Nkwengulila G. Plasmodium falciparum msp-2 genotype and multiplicity of infections among children under five years uncomplicated malaria in Kibaha Tanzania. J Parasitol Res. 2015;2015:721201.

31. Some AF, Bazie T, Zongo I, Yerbanga RS, Nikiéma F, Neya C, et al. Plasmodium falciparum msp 1 and msp 2 genetic diversity and allele frequencies in parasites isolated from symptomatic malaria patients in Bobo-Dioulasso. Burkina Faso Parasites Vectors. 2018;11:323.
32. Mustafa SO, AbdelHamid MM, Aboud MA, Amin M, Munner MS, Yasin K, et al. Genetic diversity and multiplicity of Plasmodium falciparum merozoite surface protein 2 in field isolates from Sudan. F1000 Res. 2017;6:1790.

33. Hamid MM, Mohammed SB, El Hassan IM. Genetic diversity of Plasmodium falciparum field isolates in Central Sudan inferred by PCR genotyping of merozoite surface protein 1 and 2. N Am J Med Sci. 2013;5:95-101.

34. Nikhoma SC, Nair S, Al-Saai S, Ashley E, McGready R, Phyo AP, et al. Population genetics correlates of declining transmission in human pathogen. Mol Ecol. 2013:22:273-85.

35. Escalante AA, Ferreira MU, Vinetz JM, Volkman SK, Cui L Gamboa D, et al. Malaria molecular epidemiology: lessons from the International Centers of Excellence for Malaria Research Network. Am J Trop Med Hyg. 2015;93 Suppl 3:79-86.

36. Kateera F, Nsobya SL, Tukwasibwe S, Mens PF, Hakizimana E, Grobusch MP, et al. Malaria case clinical profiles and Plasmodium falciparum parasite genetic diversity : a cross sectional survey at two sites of different malaria transmission intensities in Rwanda. Malar J. 2016;15:237.

37. Anthony TG, Conway DJ, Cox-Singh J, Matusop A, Ratnam S, Shamsul S, et al. Fragmented population structure of Plasmodium falciparum in a region of declining endemicity. J Infect Dis. 2005:191:1558-64.

38. Khaireh BD, Assefa A, Guessod HH, Basco LK, Khaireh MA, Pascual A, et al. Population genetics analysis during the elimination process of Plasmodium falciparum in Djibouti. Malar J. 2013;12:201.

39. Soulama I, Nébié I, Ouédraogo A, Gansane A, Diarra A, Tiono AB, et al. Plasmodium falciparum genotypes diversity in symptomatic malaria of children living in an urban and a rural setting in Burkina Faso. Malar J. 2009;8:135.

40. Atroosh WM, Al- Mekhlafi HM, Mahdy MA, Saif-Ali R, Al-Mekhlafi AM, Surin J. Genetic diversity of Plasmodium falciparum isolates from Pahang, Malaysia based on MSP-1 and MSP-2 gene. Parasite Vectors. 2011;4:233.

41. Adjah J, Fiadzoe B, Ayanful-torgby R, Amoah LE. Seasonal variations in Plasmodium falciparum genetic diversity and multiplicity of infection in asymptomatic children living in southern Ghana. BMC Infect Dis. 2018;18:432.

42. Mayor A, Saute F, Aponte JJ, Almeda J, Gómez-Olivé FX, Dgedge M, et al. Plasmodium falciparum multiple infections in Mozambique, its relation to other malariological indices and to prospective risk of malaria morbidity. Trop Med Int Health. 2003;8:3-11.

43. Carneiro I, Roca-Feltrer A, Griffin JT, Smith L, Tanner M, Schellenberg JM, et al. Age-patterns of malaria vary with severity, transmission intensity and seasonality in sub-Saharan Africa: a systematic review and pooled analysis. PLOS ONE. 2010;5:e8988.

44. Vafa M, Troye-Blomberg M, Anchang J, Garcia A, Migot-Nabias F. Multiplicity of Plasmodium falciparum infection in asymptomatic children in Senegal : relation to transmission, age and erythrocyte variants. Malar J. 2008;7:17.

45. Pinkevych M, Petravic J, Bereczky S, Rooth I, Färnert A, Davenport MP. Understanding the relationship between Plasmodium falciparum growth rate and multiplicity of infection. J Infect Dis. 2015;211:1121-7.

46. Smith T, Beck Hp, Kitua A, Mwankusye S, Felger I, Fraser-Hurt N. Age dependence of the multiplicity of Plasmodium falciparum, infections and of other malariological indices in an area of high endemicity. Trans R Soc Trop Med Hyg.1999:93 Suppl 1:15-20.

47. Agyeman-budu A, Brown C, Adjei G, Adams M, Dosoo D, Dery D, et al. Trends in multiplicity of Plasmodium falciparum infections among asymptomatic residents in the middle belt of Ghana. Malar J. 2013;12:22

48. Ogouye'mi-Hounto A, Gazard DK, Ndam N, Topanou E, Garba O, Elegbe P, et al. Genetic polymorphism of merozoite surface protein-1 and merozoite surface protein-2 in Plasmodium falciparum isolates from children in South of Benin. Parasite. 2013;20:37.

49. Pembe IM, Ndounga M, Malonga FV, Bitemo M, Ntoumi F. Genetic polymorphisms of merozoite surface protein-1 and merozoite surface protein-2 in Plasmodium falciparum isolates from Brazzaville Republic of Congo. Malar J. $2011 ; 10: 276$.

50. Karl S, White MT, Milne GJ, Gurarie D, Hay SI, Barry AE, Felger I, Mueller I. Spatial effects on the multiplicity of Plasmodium falciparum infections. PLoS ONE. 2016;11:e0164054.

\section{Publisher's Note}

Springer Nature remains neutral with regard to jurisdictional claims in published maps and institutional affiliations. 